\begin{tabular}{c|c|c}
\hline \hline Vol. 272: 93-98, 2004 & MARINE ECOLOGY PROGRESS SERIES \\
Mar Ecol Prog Ser & Published May 19 \\
\hline
\end{tabular}

\title{
Are mangroves a limiting resource for two coral reef fishes?
}

\author{
Benjamin S. Halpern ${ }^{1,2, *}$ \\ ${ }^{1}$ National Center for Ecological Analysis and Synthesis, Santa Barbara, California 93101, USA \\ ${ }^{2}$ Ecology and Evolutionary Biology, 100 Shafer Road, University of California, Santa Cruz, California 95060, USA
}

\begin{abstract}
Nearshore marine habitats, such as seagrass beds and mangroves, are generally assumed to be key nurseries for many marine species. Few studies, however, have examined relationships between the characteristics of juvenile habitats and the size of adult populations, although such studies are essential for confirming and quantifying the nursery function of these habitats. In this paper I describe the results of surveys of adult populations of 2 coral reef fish species (the yellowfin mojarra Gerres cinereus and the schoolmaster Lutjanus apodus) that are thought to be dependent on mangroves as nurseries in the Virgin Islands, Caribbean Sea, to determine if the size of nearby mangrove stands and their proximity to adult reef habitat are related to adult densities. The results indicate that these 2 factors do not affect adult fish densities on coral reef patches. However, evidence suggests that a relationship between the island-wide size of mangroves and adult fish densities and population sizes exists for at least 1 fish species at the island scale, indicating that juvenile habitat may limit adult fish numbers for some species at this scale.
\end{abstract}

KEY WORDS: Mangroves - Juvenile habitat $\cdot$ Juvenile bottleneck $\cdot$ Lutjanus apodus $\cdot$ Gerres cinereus $\cdot$ Virgin Islands

Resale or republication not permitted without written consent of the publisher

\section{INTRODUCTION}

Nearshore marine ecosystems, such as seagrass beds and mangrove forests, are thought to provide crucial nursery habitats for many marine species (reviewed in Blaber 2000, Beck et al. 2001). Much of the evidence for the use of these habitats as nurseries comes from studies that have focused on how particular characteristics of the juvenile habitat lead to larger juvenile populations, without determining if or how processes at the juvenile stage ultimately affect adult populations (Beck et al. 2001). Establishing this link between juvenile and adult populations is critical for distinguishing between habitats that are productive for resident individuals and habitats that are actually serving as nurseries (i.e. supplying great numbers of individuals to adult habitats). In other words, a juvenile habitat may be extremely productive, but if no juveniles from that habitat successfully migrate to the adult population, then the habitat productivity never translates into reproductive output for the species.
Habitat size and relative location within a landscape may play important roles in determining nursery productivity (Beck et al. 2001). Demographic bottlenecks due to limited habitat availability have been shown for several species (Steger 1987, Wahle \& Steneck 1991, Beck 1995, 1997), and relationships between the size of available juvenile habitat and adult population size may exist for several species (reviewed in Blaber 2000). However, this relationship remains equivocal. Furthermore, the distance between juvenile and adult habitats may affect the number of juveniles that successfully migrate to adult habitats. Mortality may be greater with increasing distance, or individuals may have difficulty finding an appropriate adult habitat if it is far from the juvenile habitat. In fact, patch size and the distance between patches are known to play a key role in determining the population size and persistence of species on islands (MacArthur \& Wilson 1967) and in metapopulations (Hanski \& Gilpin 1997), but few studies to date have directly tested the role of these factors in controlling population sizes of species that use nursery 
habitats. Recent evidence suggests that mangrove patch size and proximity to coral reefs may be important for limiting adult population sizes of some coral reef fishes (Blaber 2000, Nagelkerken et al. 2000, 2002), although this evidence remains limited in extent.

To test if the population density of reef fishes that are dependent on mangroves as nursery habitat is related to mangrove size and location, I conducted surveys of the densities of 2 species of coral reef fishes on patches of reef that varied in distance from mangroves stands of varying size. Correlations between these variables are used to address the following questions: (1) Are densities of these species on a reef a function of the size of the nearest mangrove stand? (2) Are fish densities a function of the distance between study reef and the nearest mangrove? (3) Is the role of either factor in controlling fish densities scale-dependent?

\section{MATERIALS AND METHODS}

Study site and species. I conducted surveys around 5 Virgin Islands in the Caribbean Sea (see Fig. 1). These islands are part of the northern Lesser Antilles and include St. John, St. Thomas and St. Croix in the US Virgin Islands and Virgin Gorda and Tortola in the British Virgin Islands. Shallow, nearshore reefs surveyed in this study consist mostly of medium-sized (100 to $300 \mathrm{~m}$ in length) patches contiguous with the shoreline and fringed by large sandy areas, except for some regions of St. Croix that consist of continuous barrier reef. St. Croix is separated from the other islands by a submerged canyon $3 \mathrm{~km}$ in depth, whereas all the other Virgin Islands are separated by channels about $30 \mathrm{~m}$ deep. Both red mangroves Rhizophora mangle and black mangroves Avicennia germinans are present around these islands but are limited in extent and vary in the size of individual stands, their proximity to study reefs and the total mangrove area per island. I classified each mangrove stand as pristine (no shoreline development in or near mangroves), partially developed (mangroves and development intermixed), or fully developed (most of shoreline developed, and mangrove area used as a harbor), and calculated the average rank of the mangrove stands around each island. Data from Navassa Island (Miller 2003), an island $\sim 50 \mathrm{~km}$ from Haiti that has no mangrove habitat, were also included for island-scale analyses. Survey methods for Miller's study (2003) were different from those used here, so only data for Gerres cinereus could be used because no individuals of this species were observed.

Adults from 2 species of reef fishes, the schoolmaster Lutjanus apodus and the yellowfin mojarra Gerres cinereus, were surveyed. In the Virgin Islands, these species appear to be dependent on mangroves as nurseries; small juveniles ( $<10 \mathrm{~cm}$ total length, TL) are found only in mangrove habitats, while fish larger then about $15 \mathrm{~cm}$ TL are rarely seen in mangroves (Adams \& Ebersole 2002, and author's pers. obs.).

Survey design. Fish populations were surveyed at a total of 69 haphazardly selected non-contiguous reef sites around each of the 5 Virgin Islands (see Fig. 1). All surveys were conducted along the sand/reef edge of study reefs. Reef sites were chosen based on their accessibility from roads along the shore and were of varying distance (0.1 to $18 \mathrm{~km}$ ) from mangrove stands of varying size $\left(0.0007\right.$ to $\left.0.786 \mathrm{~km}^{2}\right)$. Surveys were conducted from June 22 to July 4, 2001.

At each site, six 5 min timed transects were swum at haphazardly chosen locations, similar to the method described by Greene \& Alevizon (1989). This method is good for describing relative differences in fish densities at different sites, but has limitations when trying to calculate population size, since transects are not spatially explicit. At some sites it was not possible to swim all 6 transects because reef patches were too small;

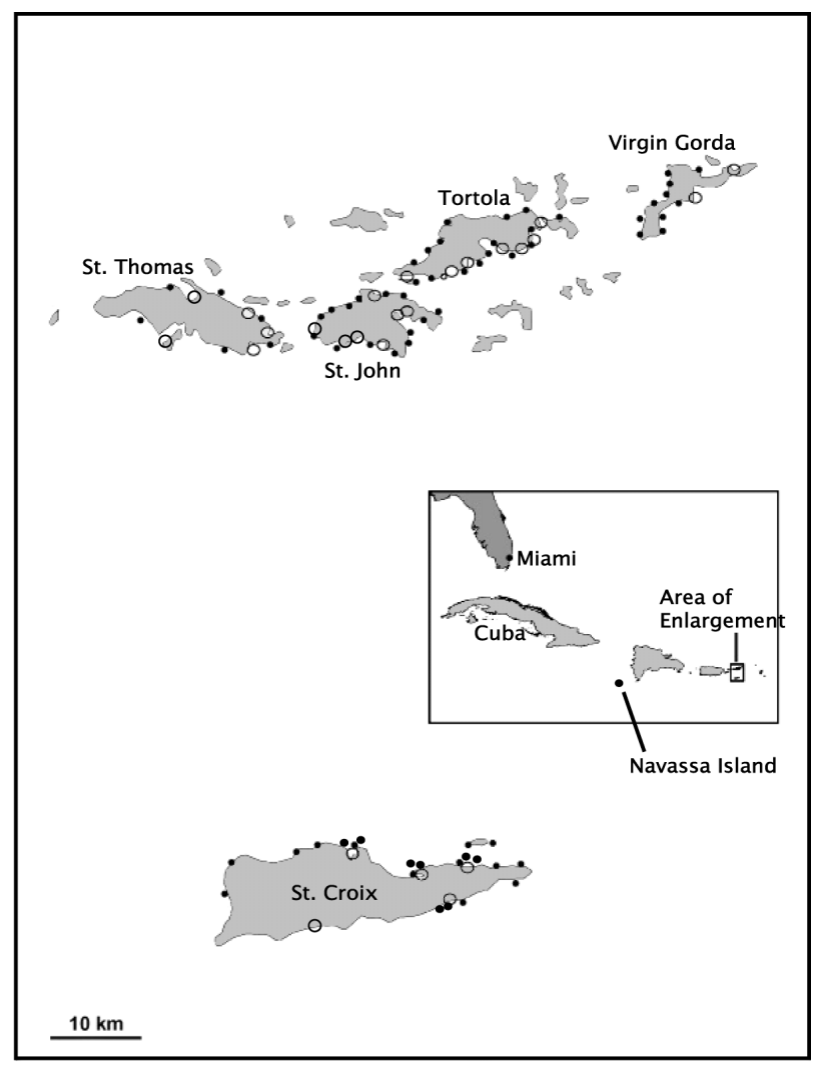

Fig. 1. The Virgin Islands, Caribbean, showing locations of stands of mangrove (O) and survey $(\bullet)$ sites. Survey sites around islands were chosen haphazardly according to accessibility from the road, except around St. Croix where many sites were chosen to be near but at varying distances from mangrove patches 
consequently, only 5 transects were conducted at 6 sites, 4 transects at 4 sites, 3 transects at 1 site, and 2 transects at 3 sites. Transect values from each site were averaged to give site values, and all transects within an island were averaged to give island values. All transects were examined via snorkel-diving above the $3 \mathrm{~m}$ depth contour (depth range $=1.5$ to $5 \mathrm{~m}$ ). Both species are common at this depth, but can also be found down to $15 \mathrm{~m}$ (Gerres cinereus) and $60 \mathrm{~m}$ (Lutjanus apodus; R. Froese \& D. Pauly 2003: FishBase; available at www.fishbase.org).

During each timed swim, an assistant or I would count the number of Gerres cinereus and Lutjanus apodus seen at any distance from the transect. We would also search in and under large reef structures to look for hiding fishes, and would track fishes, to ensure we did not count a fish twice. Visibility was estimated to the nearest $1 \mathrm{~m}$, and during each transect data were collected on the percent of complex reef present (defined as reef structure large enough to hide adult fishes, and binned into $5 \%$ categories) and the overall complexity rank of the transect, scaled from 0 (all flat) to 5 (high 3 dimensionality along the entire transect). These latter data were used to characterize and compare reefs among sites and islands.

High-resolution aerial photographs taken by the National Oceanographic and Atmospheric Association (NOAA 2003: Biogeography Program, available at: http://biogeo.nos.noaa.gov/products/data/photos/ usvi.shtml) of the US Virgin islands and most of Tortola were used in conjunction with National Institute of Health (NIH) image software to calculate linear extent of mangrove stands and the distance between mangroves and study reefs for these islands. For mangroves and study reefs in Eastern Tortola and Virgin Gorda, for which aerial photographs were not available, the linear coastal extent and location of mangroves was noted on nautical charts that were then scanned to make digital images to be used in calculating these measures. All measurements using $\mathrm{NIH}$ Image software were made 3 times and average values were used for analyses.

The lengths of mangrove stands were multiplied by a width of $2 \mathrm{~m}$ to get a total area of submerged mangrove. Randomly chosen transects at Gallows Bay and Salt River in St. Croix showed the average width of mangroves submerged during high tide (i.e. accessible to fishes) to be about $2 \mathrm{~m}$ (mean $\pm \mathrm{SD}=2.14 \pm 1.1 \mathrm{~m}$; $\mathrm{n}=8$ ). Because most mangrove stands on the other islands were inaccessible, I used this width of $2 \mathrm{~m}$ to calculate submerged mangrove area for all mangrove stands. Comparison of these values to data from benthic habitat GIS shape files available for the 3 US Virgin Islands (Kendall et al. in press) confirm accu- racy of the method (individual mangrove stand size: paired $t$-test, $t=0.54, \mathrm{p}=0.60$; total island mangrove size: paired $t$-test, $t=-1.97, \mathrm{p}=0.08$ ).

The effect of mangrove stand size on adult population density at the nearest study reef was tested at the small scale, where each site was included independently, and at the larger (island) scale, where data were averaged for all sites from an island. The effect of distance between study reef patch and the nearest mangrove stand was tested only at the small scale, with each site as an independent datum.

\section{RESULTS}

Mangrove habitat was distributed among 26 stands, with 2 to 7 stands per island (Fig. 1). Stands ranged in size from 0.0007 to $0.786 \mathrm{~km}^{2}$ (mean $\pm \mathrm{SD}=0.078 \pm$ $0.176 \mathrm{~km}^{2}$ ) and the total mangrove area on any one island from 0.004 to $1.33 \mathrm{~km}^{2}$. Distances between mangroves and study reefs ranged from 0.12 to $17.95 \mathrm{~km}$ $($ mean $\pm \mathrm{SD}=4.91 \pm 4.41 \mathrm{~km})$, with a third of the reef sites ( $\mathrm{n}=23$ ) being $<1.5 \mathrm{~km}$ from a stand of mangroves. Average amount of complex reef structure and overall complexity rankings were significantly different between islands (ANOVA, df $=4,372, F=10.65$, $\mathrm{p}<0.0001$ and $\mathrm{df}=4,372, F=13.74, \mathrm{p}<0.0001$, respectively). Pairwise comparisons showed that Virgin Gorda, Tortola, and St. John had significantly higher amounts of complex reef than St. Thomas and St. Croix, and that Virgin Gorda's complexity ranking was significantly higher than all other islands.

Visibility at each site averaged about $8 \mathrm{~m}$ (mean $\pm \mathrm{SE}=7.94 \pm 0.20$; range $=2$ to $18 \mathrm{~m}$ ). Although average visibility across sites and islands differed significantly (ANOVA: df $=67,316, F=19.81, \mathrm{p}<0.0001$; $\mathrm{df}=$ $4,379, F=14.78, \mathrm{p}<0.0001$; for sites and islands, respectively), average densities for neither species were a function of visibility at either scale (linear regression, sites: df $=1,67, F=0.23, \mathrm{p}=0.63$ for Gerres cinereus, $\mathrm{df}=1,67, F=0.00, \mathrm{p}=0.99$ for Lutjanus apodus; islands: $\mathrm{df}=1,3, F=0.16, \mathrm{p}=0.72$ for $G$. cinereus, $\mathrm{df}=$ $1,3, F=1.52, \mathrm{p}=0.30$ for $L$. apodus). Therefore, the relative density measurements are likely to be accurate.

Analyses of mean values from all sites show no interactive or independent effects of juvenile habitat (mangrove) size and distance between mangrove and reef habitats on adult density at a site (average number of fishes per transect; Table 1). When site data were averaged for each island and correlated with total island mangrove size, some significant results emerged. Because there was high variance in density values among sites, average island population density did not differ significantly between islands for either species (ANOVA: $F=0.23, \mathrm{p}=0.99 ; F=1.24, \mathrm{p}=0.31$; for $G e r$ - 
Table 1. Gerres cinereus and Lutjanus apodus. Results of linear and log-linear multiple regression analyses using distance between reef and mangroves (D) and mangrove stand size (S) as independent variables and average population density of the 2 fish species as the dependent variable

\begin{tabular}{|c|c|c|c|c|c|c|c|}
\hline \multirow[t]{2}{*}{ Analysis } & \multirow[t]{2}{*}{$\mathrm{df}$} & \multicolumn{3}{|c|}{ G. cinereus } & \multicolumn{3}{|c|}{ L. apodus } \\
\hline & & SS & $F$ & $\mathrm{p}$ & SS & $F$ & $\mathrm{p}$ \\
\hline \multicolumn{8}{|l|}{ Linear } \\
\hline Distance (D) & 1,66 & 0.006 & 0.002 & 0.96 & 9.763 & 1.52 & 0.22 \\
\hline Size $(\mathrm{S})$ & 1,66 & 1.835 & 0.58 & 0.45 & 0.105 & 0.02 & 0.90 \\
\hline \multicolumn{8}{|l|}{ Log-Linear } \\
\hline Distance (D) & 1,66 & 0.021 & 0.01 & 0.94 & 22.405 & 3.60 & 0.06 \\
\hline Size (S) & 1,66 & 0.697 & 0.22 & 0.64 & 0.138 & 0.02 & 0.88 \\
\hline
\end{tabular}

of population size of L. apodus. The number of active fishing licenses can serve as a proxy measure of fishing intensity around each island. In 2001, St. Thomas and St. Croix had 155 and 220 active licensed fishermen, respectively, while St. John had only 21 and Virgin Gorda and Tortola combined had 77 (pers. comm. of N. Eristhee for the British Virgin Islands, pers. comm. of S. Wear for the US Virgin Islands). The low density values for L. apodus around St. Croix and St. Thomas, therefore, could be due to high fishing pressure.

res cinereus and Lutjanus apodus, respectively). However, for G. cinereus, which is not fished, there was a highly significant log-linear relationship between average adult density and total island mangrove size (Fig. 2A; linear regression analysis on log-transformed mangrove size, $\mathrm{df}=1,4, F=39.94, \mathrm{p}=0.003, \mathrm{R}^{2}=0.91$ ).

This relationship was not evident for Lutjanus apodus (Fig. 2B; linear regression analysis using log-transformed mangrove size, $\mathrm{df}=1,3, F=0.04, \mathrm{p}=0.85$ ). However, fishing intensity may be altering the patterns
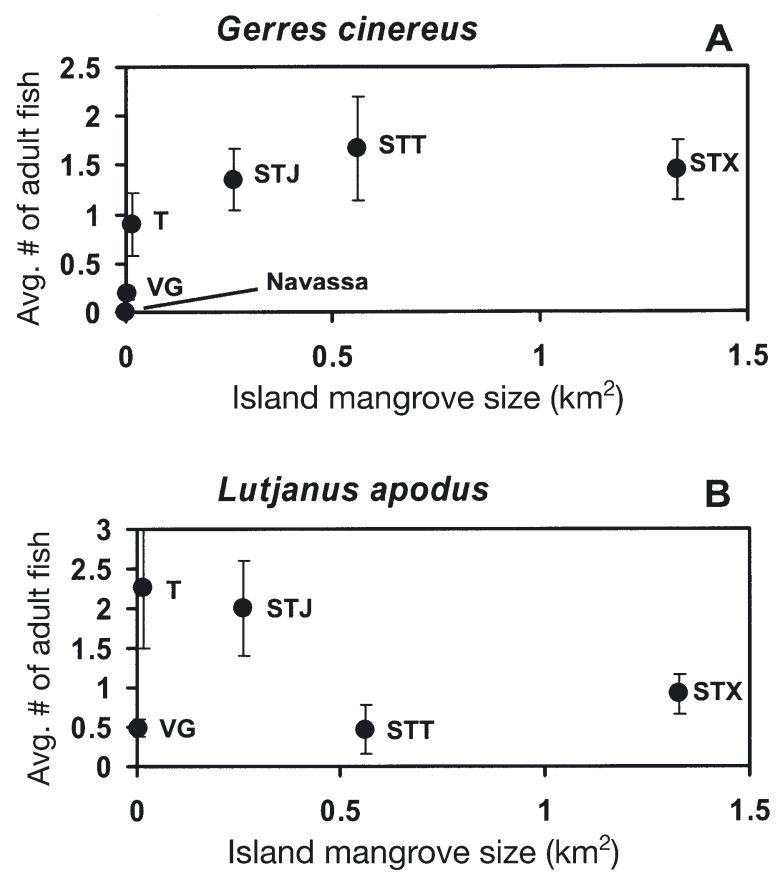

Fig. 2. Gerres cinereus and Lutjanus apodus. Average number of adults per transect counted on timed swims over reef patches as a function of total area of mangroves per island. Each point represents an island. Navassa Island data (Miller 2003) could be included only for G. cinereus (polulation size zero) because of differences in survey methods. Data are means \pm SE. VG: Virgin Gorda; T: Tortola; STJ: St. John; STT: St. Thomas; STX: St. Croix
Mangrove quality had no effect on adult population densities at either scale. I found no significant differences among adult population densities on reefs that were closest to mangrove stands of different qualities (1-way ANOVA, df $=2,67, F=0.01, p=0.99$ and $F=$ $1.87, \mathrm{p}=0.16$ for Lutjanus apodus and Gerres cinereus, respectively). There was also no significant relationship between average island adult population density and average island mangrove quality (linear regression analysis, $\mathrm{df}=1,4, F=1.55, \mathrm{p}=0.30$ and $F=0.09$, $\mathrm{p}=0.78$ for $G$. cinereus and $L$. apodus, respectively), although sample size was small for this test. In fact, the island with the most pristine mangroves (Virgin Gorda) had the lowest densities of both fish species, whereas the island with the most degraded mangrove stands (Tortola) had the highest population densities for L. apodus.

\section{DISCUSSION}

The results of this study suggest that for 2 species of reef fishes that are dependent on mangroves as nurseries, adult populations on reefs are not limited by mangrove stand size or proximity at the local (small) scale (hundreds of meters to kilometers), but may be limited by the amount of mangroves around an entire island. This island-wide pattern is evident in correlations between average adult density and total mangrove area for Gerres cinereus, but less so for Lutjanus apodus.

There are 2 likely reasons for why the island-wide relationship was clear for Gerres cinereus but less apparent for Lutjanus apodus. First, high fishing pressure in St. Thomas and St. Croix would only affect $L$. apodus (G. cinereus are not fished), which may explain why average population densities for this species were so low on these islands. Second, the relatively high mobility of $L$. apodus may act to obscure potential relationships between population size and habitat size. 
Data from Navassa Island (Miller 2003) show how species mobility may affect local population size; the island had no yellowfin mojarra of any size but some large schoolmasters. Although some L. apodus may have recruited to the island in the past, it is also likely that some individuals swam from Haiti to Navassa Island.

These results are in contrast to those from Curaçao, where fish densities of nursery species decreased with increasing distance from the mouth of a bay containing nursery habitats (Nagelkerken et al. 2000). Further study is necessary to explore why results varied between these locations, although differences in features of the reef, the productivity of the bays containing nursery habitats, and the number of mangrove stands around each island may affect dispersal patterns and distributions of individuals, in turn creating or obscuring a relationship between population size and distance from the nearest nursery habitat. Interestingly, results from this study show that reef structure did not create this relationship in the Virgin Islands, and in fact may have obscured the pattern (i.e. the lowest adult densities were on the most complex reefs).

These results suggest that if a juvenile habitat bottleneck exists at the island-scale, it is removed once juvenile habitat size exceeds a relatively small size. Warner \& Hughes (1989) showed that the ability of adult populations of long-lived species to store pulses of recruits makes recruitment limitation possible only when recruitment is very low. A similar process may be occurring here, where the long lifespan of the 2 species (congenerics live 25 to $50 \mathrm{yr}$; Burton 2001, Wilson \& Nieland 2001, Newman \& Dunk 2003) relative to the time they spend in the juvenile habitat (several months at most), causes the juvenile habitat to be a limiting factor only when it is particularly scarce.

Other factors are likely to be important for creating or obscuring the relationship between juvenile habitat size and adult population size. Recruitment to mangrove patches may vary significantly, depending on the location of the mangroves relative to larval delivery paths. Similarly, mangrove quality may affect how this habitat limits population size, although the results from this study suggest that the condition of the mangrove stands was not likely to be a factor influencing these results. Finally, in other locations, juveniles of these species have been found in habitats other than mangroves (Nagelkerken et al. 2001), suggesting that the relationship between adult population size and mangrove habitat size may vary geographically depending on how necessary the mangrove habitat is for juveniles of the species in the particular location. Regardless of these other possible factors, in this study juvenile habitat (mangrove) size appeared to be an important limiting factor for adult population size for at least 1 coral reef species.

There are 2 particularly important implications of this work. First, determining the role that juvenile habitats play in limiting population size is necessarily a complex question that is likely to have different answers for each species in each location. Given the large number of species that use distinct juvenile habitats, this issue merits more attention in ecological research. Second, results from this work highlight the need to carefully evaluate the actual role juvenile habitat plays in limiting adult population size when developing conservation and management plans for species that use nursery habitats. Although nursery habitats are likely to exist and to be important for many species, conservation money and time are always limited and may be more judiciously spent helping to protect and restore adult reef habitats.

Acknowledgements. This work was supported in part by a NSF Graduate Research Fellowship and by a Partnership for the Interdisciplinary Study of Coastal Oceans (PISCO), funded by the David and Lucille Packard Foundation. Thanks to R. Warner, S. Gaines, S. Cooper and several anonymous reviewers for helpful comments on earlier versions of this manuscript.

\section{LITERATURE CITED}

Adams AJ, Ebersole JP (2002) Use of back-reef and lagoon habitats by coral reef fishes. Mar Ecol Prog Ser 228: $213-226$

Beck MW (1995) Size-specific shelter limitation in stone crabs: a test of the demographic bottleneck hypothesis. Ecology 76:968-980

Beck MW (1997) A test of the generality of the effects of shelter bottlenecks in four stone crab populations. Ecology 78: $2487-2503$

Beck MW, Heck KL Jr, Able K, Childers D and 9 others (2001) The identification, conservation and management of estuarine and marine nurseries for fish and invertebrates. BioScience 51:633-641

Blaber SJM (2000) Tropical estuarine fishes: ecology, exploitation, and conservation. Blackwell Science, London

Burton ML (2001) Age, growth, and mortality of gray snapper, Lutjanus griseus, from the east coast of Florida. Fish Bull Fish Wildl Serv US 99:254-265

Greene LE, Alevizon WS (1989) Comparative accuracies of visual assessment methods for coral reef fishes. Bull Mar Sci 44:899-912

Hanski IA, Gilpin ME (1997) Metapopulation biology: ecology, genetics, and evolution. Academic Press, San Diego, CA

Kendall MS, Buja KR, Christensen JD, Kruer CR, Monaco ME (2004) The seascape approach to coral ecosystem mapping: an integral component of understanding the habitat utilization of reef fish. Bull Mar Sci (in press)

MacArthur RH, Wilson EO (1967) The theory of island biogeography. Princeton University Press, Princeton, NJ

Miller MW (ed) (2003) Status of reef resources of Navassa Island: cruise report Nov. 2002. NOAA Tech Memo NMFS (SEFSC-501)

Nagelkerken I, Dorenbosch M, Verberk WCEP, Cocheret de la Moriniere E, van der Velde G (2000) Importance of shallow- 
water biotopes of a Caribbean bay for juvenile coral reef fishes: patterns in biotope association, community structure and spatial distribution. Mar Ecol Prog Ser 202:175-192

Nagelkerken I, Kleijnen S, Klop T, van den Brand RACJ, Cocheret de la Moriniere E, van der Velde G (2001) Dependence of Caribbean reef fishes on mangroves and seagrass beds as nursery habitats: a comparison of fish faunas between bays with and without mangroves/ seagrass beds. Mar Ecol Prog Ser 214:225-235

Nagelkerken I, Roberts CM, van der Velde G, Dorenbosch M, van Riel MC, Cocheret de la Moriniere E, Nienbuis PH (2002) How important are mangroves and seagrass beds for coral-reef fish? The nursery hypothesis tested on an island scale. Mar Ecol Prog Ser 244:299-305

Newman SJ, Dunk IJ (2003) Age validation, growth, mortal-

Editorial responsibility: Otto Kinne (Editor),

Oldendorf/Luhe, Germany ity, and additional population parameters of the goldband snapper (Pristipomoides mulitdens) off the Kimberley coast of northwestern Australia. Fish Bull 101:116-128

Steger R (1987) Effects of refuges and recruitment on gonodactylid stomatopods, a guild of mobile prey. Ecology 68: 1520-1533

Wahle RA, Steneck RS (1991) Recruitment habitats and nursery grounds of the American lobster Homarus americanus: a demographic bottleneck? Mar Ecol Prog Ser 69: 231-243

Warner RR, Hughes TP (1989) The population dynamics of reef fish. Proc 6th Int Coral Reef Symp 1:149-155

Wilson CA, Nieland DL (2001) Age and growth of red snapper, Lutjanus campechanus, from the northern Gulf of Mexico off Louisiana. Fish Bull 99:653-664

Submitted: May 9, 2003; Accepted: December 16, 2003 Proofs received from author(s): May 6, 2004 